\title{
Neoadjuvant Imatinib Therapy Followed by Intersphincteric Resection for Low Rectal Gastrointestinal Stromal Tumors
}

\author{
MANABU KANEKO, HIROAKI NOZAWA, SHIGENOBU EMOTO, KOJI MURONO, \\ KAZUHITO SASAKI, KENSUKE OTANI, TAKESHI NISHIKAWA, TOSHIAKI TANAKA, \\ TOMOMICHI KIYOMATSU, KEISUKE HATA, KAZUSHIGE KAWAI and TOSHIAKI WATANABE \\ Department of Surgical Oncology, Faculty of Medicine, The University of Tokyo, Tokyo, Japan
}

\begin{abstract}
Background/Aim: Intersphincteric resection (ISR) aims to preserve anal function in patients with very low rectal tumors. Here, we analyzed patients who underwent neoadjuvant imatinib therapy followed by ISR for low rectal gastrointestinal stromal tumors (GISTs). Patients and Methods: We retrospectively analyzed patients with low rectal GISTs who underwent neoadjuvant imatinib therapy and ISR between January 2013 and December 2015 at the University of Tokyo hospital. Results: The study included 4 men and 1 woman, with a median age of 67 years (range $=45-67$ ). All patients received $400 \mathrm{mg}$ of neoadjuvant imatinib once daily for the median duration of 4 months (range $=3-12$ ). Microscopically, $R 0$ resection was performed in 4 patients, and RI, in 1 patient. There was 1 recurrence event during the median follow-up duration of 35 months. Conclusion: Neoadjuvant imatinib therapy and ISR for low rectal GISTs is a challenging, but promising, alternative to achieve complete resection margins and preserve anal function.
\end{abstract}

Gastrointestinal stromal tumors (GISTs) are the most common mesenchymal neoplasms of the gastrointestinal tract, and occur in about 10-15 people per million per year (1-3). GISTs have the features of leiomyosarcomas and neural tumors (4-6), appear to be derived from the interstitial cells of Cajal, and harbor activating mutations in the KIT (a receptor tyrosine kinase or RTK, also called CD117) gene (7). GISTs are commonly located in the stomach $(50 \%)$ and the proximal small intestine (35\%), but uncommonly in the

Correspondence to: Dr. Manabu Kaneko, Department of Surgical Oncology, Faculty of Medicine, The University of Tokyo, 7-3-1 Hongo, Bunkyo-ku Tokyo 113-8655, Japan. Tel: +81 33815 5411, Fax: +81 338116822, e-mail: m.kaneko@fancy.ocn.ne.jp

Key Words: Gastrointestinal stromal tumor, low rectum, neoadjuvant therapy, imatinib. rectum (5\%) (8). Surgery is the only curative treatment for resectable GISTs. For locally advanced low rectal GISTs, radical excisions are performed with sphincter-sparing procedures, abdominal perineal resections, or more extended surgery, accompanied by the removal of adjacent organs. However, the recurrence rates are moderately high, about 40$60 \%$ within 2 years of treatment, despite undergoing complete surgical resections (9).

Currently, imatinib mesylate, a small-molecule inhibitor of the proto-oncogene $c$-KIT tyrosine kinase, is the first-line treatment for patients with locally advanced or metastatic GISTs, and is proven to improve recurrence-free survivals in adjuvant settings (10-13). Additionally, imatinib also provides a new approach for the treatment of GISTs, in neoadjuvant settings (14-16). In this regard, a few reports have described the efficacy of neoadjuvant imatinib therapy (17-23) and the combination of neoadjuvant imatinib therapy and intersphincteric resection (ISR) for the treatment of low rectal GISTs $(22,23)$.

The present study included patients who underwent neoadjuvant imatinib therapy followed by ISR for low rectal GISTs, and evaluated the responses of rectal GISTs to imatinib, based on the radiological assessments of tumors, and the outcomes of subsequent surgeries.

\section{Patients and Methods}

Patients. We retrospectively analyzed 5 patients with low rectal GISTs who underwent neoadjuvant imatinib therapy followed by ISR, between January 2013 and December 2015, at the University of Tokyo Hospital. Medical records of these patients were retrieved from our registry, and patient demographics, tumor characteristics, radiological findings, surgical outcomes, and postoperative followup data were collected. The study protocol was approved by the Ethics Committee of the University of Tokyo.

All patients underwent digital rectal examinations, colonoscopy, and imaging by computed tomography (CT) and magnetic resonance imaging (MRI), for disease evaluation. Additionally, they underwent pre-treatment core needle biopsies to confirm histology, and displayed positive immunostaining for CD117 (c-KIT). CT 
scans were obtained for staging before initiating treatment, and resectability was assessed based on MRI scans. Maximum tumor diameters were measured based on MRI or CT scans. Colonoscopy, CT, and MRI were performed repeatedly every 3 months to measure tumor responses to imatinib treatment. Patients with favorable responses were offered surgical treatment, whereas those with stable disease or the need for permanent stoma continued neoadjuvant therapy for the next 3 months. Pathology reports were reviewed to identify tumor histopathological characteristics, molecular analysis, and microscopic clearance. Risk classification was determined using the Joensuu classification (24). The disease evaluation was performed per the Response Evaluation Criteria in Solid Tumors (RECIST) (25)

Postoperative follow-up included the following procedures: physical examinations every 3 months, chest and abdominal CT scans every 6 months, and colonoscopy every 12 months. Adjuvant imatinib was administered to 1 selected patient for 3 years. Local and distant recurrences were defined by radiographic and histological findings.

Statistical analysis. Descriptive statistics are presented as median (range). The parametric two-tailed paired $t$-test was used to analyze changes in tumor sizes. The reported $p$-values are two-tailed, and values $<0.05$ were considered significant. Data were analyzed using EZR v.1.33 for Windows software (Saitama Medical Center, Jichi Medical University, Saitama, Japan), which is a graphical user interface for R (The R Foundation for Statistical Computing, Vienna, Austria) (26).

\section{Results}

A total of 4 men (80\%) and 1 woman (20\%), with a median age of 67 years (range $=45-75$ ), were included in this study. Laparoscopic ISR was performed in all patients. The distal resection lines were at the dentate line (partial ISR), in all patients. No patient was lost to follow-up. The median maximum tumor diameter at presentation was $44 \mathrm{~mm}$ (range $=40-64 \mathrm{~mm}$ ). The median distance from anal verge to the lower margin of the tumor at surgery was $3 \mathrm{~cm}$ (range $=2-4$ ). Based on the Joensuu classification, 2 tumors (40\%) were classified as high-risk and 3 (60\%), as low-risk. All patients exhibited positive immunostaining for KIT. Demographic and clinical data of patients are presented in Table I.

Patient characteristics and treatment outcomes are presented in Table II. All patients were administered neoadjuvant imatinib at $400 \mathrm{mg}$, once daily, for the median duration of 4 (range $=3-12$ ) months. Dermatologic side effects occurred in 3 patients. In 2 of them, neoadjuvant imatinib therapy was ceased 3 or 4 months later, and surgery was performed. The median maximum tumor diameter at the time of surgery decreased significantly to $25 \mathrm{~mm}$ (range $=18$ $42 \mathrm{~mm})(p<0.01)$ (Figure 1). All patients experienced tumor reductions (partial responses as classified by RECIST) that allowed sphincter-preserving procedures. Pre- and posttreatment MRI scans for a representative patient with a rectal GIST are shown in Figure 2.

\section{Maximum tumor diameter}

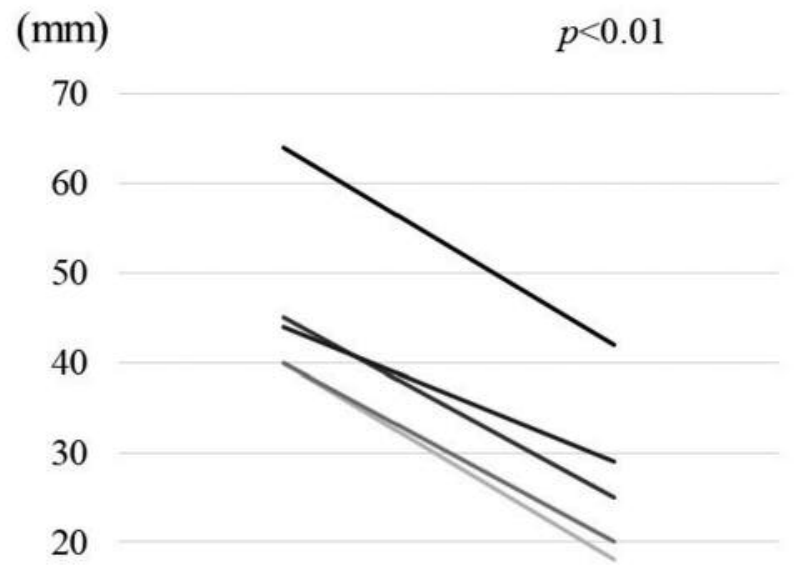

10

0

$$
\text { Before After }
$$

Figure 1. Maximum tumor diameters of rectal gastrointestinal stromal tumors, before and after neoadjuvant imatinib therapy.

Macroscopically, complete resections were achieved in all patients. The median time of surgery was $407 \mathrm{~min}$ (range $=348-768 \mathrm{~min}$ ), and the median estimated blood loss was $210 \mathrm{ml}$ (range=50-1,320 $\mathrm{ml}$ ). There were no intraoperative complications. Microscopically, R0 resection (complete resections with no residual tumors) was performed in 4 patients and R1 (tumor cells present near the resection margin) in 1. There were no deaths within 30 days of surgery. Postoperative complications were as follows: urinary tract infection and small bowel obstruction in 1 patient each, respectively. These complications were treated with conservative therapy. The median duration of postoperative hospital stay was 23 days (range $=17-29$ days).

The median follow-up period was 35 months (range $=26$ 48 months). Postoperative imatinib was administered to 1 patient who underwent $\mathrm{R} 1$ resection, and was treated for 3 years after surgery. One patient experienced lateral pelvic lymph node metastases at 23 months after surgery, and has been treated with imatinib continuously since then. The 4 remaining patients were alive at the end of the follow-up period, without any evidence of local or systemic recurrence. Ileostomies were closed in 4 patients who showed good anal function after 5-10 months and good fecal continence after stoma closure. Stoma closure was postponed in 1 patient because of insufficient anal function. All patients showed good urinary functions. 
Table I. Demographic and clinical data on patients included in the study.

\begin{tabular}{lc}
\hline Variable & \\
\hline Median age in years (range) & $67(45-75)$ \\
Male to female ratio & $4: 1$ \\
Median BMI in kg/m $\mathrm{m}^{2}$ (range) & $24.8(21.7-28.7)$ \\
ASA PS & 3 \\
1 & 2 \\
2 & $44(40-64)$ \\
Median maximum tumor diameter in mm at presentation (range) & $4(3-12)$ \\
Median duration of neoadjuvant therapy in months (range) & $3(2-4)$ \\
Median distance in cm from anal verge at surgery (range) & 3 \\
Risk classification & 2 \\
Low & 2 \\
High &
\end{tabular}

BMI: Body mass index; ASA: American Society of Anesthesiologists; PS: physical status.

Table II. Patient characteristics and outcomes of treatment.

\begin{tabular}{|c|c|c|c|c|c|c|c|c|c|c|c|c|c|c|}
\hline \multirow[t]{2}{*}{ Case } & \multirow[t]{2}{*}{$\begin{array}{c}\text { Age } \\
\text { (years) }\end{array}$} & \multirow[t]{2}{*}{ Gender } & \multirow[t]{2}{*}{$\begin{array}{c}\text { Distance } \\
\text { from anal } \\
\text { verge } \\
(\mathrm{cm})\end{array}$} & \multirow[t]{2}{*}{$\begin{array}{c}\text { Duration of } \\
\text { neoadjuvant } \\
\text { therapy } \\
\text { (months) }\end{array}$} & \multicolumn{2}{|c|}{$\begin{array}{l}\text { Maximum } \\
\text { tumor } \\
\text { diameter } \\
(\mathrm{mm})\end{array}$} & \multirow[t]{2}{*}{$\begin{array}{l}\text { Reduction } \\
\text { rate } \\
(\%)\end{array}$} & \multirow[t]{2}{*}{$\begin{array}{c}\text { Tumor } \\
\text { response } \\
\text { by } \\
\text { RECIST }\end{array}$} & \multicolumn{2}{|c|}{$\begin{array}{c}\text { Mitotic } \\
\text { count } \\
\text { (per 50 } \\
\text { HPFs) }\end{array}$} & \multirow[t]{2}{*}{$\begin{array}{c}\text { Surgical } \\
\text { margin }\end{array}$} & \multirow[t]{2}{*}{$\begin{array}{l}\text { Adjuvant } \\
\text { therapy }\end{array}$} & \multirow[t]{2}{*}{$\begin{array}{c}\text { Last } \\
\text { follow-up } \\
\text { (months) }\end{array}$} & \multirow[t]{2}{*}{ Prognosis } \\
\hline & & & & & Befor & After & & & Befor & After & & & & \\
\hline 1 & 45 & M & 2 & 6 & 40 & 18 & 55 & PR & 5 & 1 & $\mathrm{R} 1$ & + & 48 & Alive without disease \\
\hline 2 & 75 & M & 3 & 12 & 45 & 25 & 44 & PR & 5 & 0 & R0 & - & 48 & Alive without disease \\
\hline 3 & 67 & M & 3 & 3 & 44 & 29 & 34 & PR & $<5$ & 50 & R0 & - & 33 & Alive without disease \\
\hline 4 & 71 & $\mathrm{~F}$ & 4 & 4 & 64 & 42 & 34 & PR & 0 & $8-9$ & R0 & - & 35 & Alive without disease \\
\hline 5 & 67 & M & 3 & 3 & 40 & 20 & 50 & PR & $>50$ & $<5$ & R0 & - & 26 & Alive with disease \\
\hline
\end{tabular}

M: Male; F: female; RECIST: response evaluation criteria in solid tumors; HPF: high-power field; PR: partial response.

\section{Discussion}

Surgery for rectal GISTs may be difficult because they are often large in size; no standard treatment strategies have been yet established for rectal GISTs because of the small number of such cases (27). The aim of surgery for low rectal GISTs is to achieve both microscopically negative resection margins and anal sphincter preservation. For these purposes, two aspects should be considered, namely, the preoperative use of imatinib, and the surgical procedure.

Treatment with neoadjuvant imatinib for patients with locally advanced or marginally resectable GISTs offers several potential benefits, including tumor down-sizing, preventing the intraoperative rupture of the tumor, providing an opportunity to maintain the functioning of the involved organs, and reducing the risks of recurrence. In fact, treatment with neoadjuvant imatinib successfully downsizes tumors and aids the performance of organ-preserving surgeries in patients with high-risk GIST tumors arising in the gastrointestinal tract $(14,28,29)$. Fiore et al. reported that all patients with GISTs of the digestive tract showed a median reduction in tumor size of $34 \%$ with tolerable toxicities, following preoperative imatinib therapy, for a median duration of 9 months (14). Previous studies have reported response rates of $73-100 \%$ with no evidence of progressive disease following preoperative imatinib therapy in patients with rectal GISTs, for 1-60 months $(18,19,21,30)$. The European Society for Medical Oncology guidelines recommend neoadjuvant imatinib therapy for tumors under the following conditions: if $\mathrm{R} 0$ resection is not feasible, if resection could be achieved by less mutilating surgery, or if the surgical procedure could be made safer, for instance, by decreasing the blood loss and the risks of tumor rupture (31). Only a few reports have described the efficacy of neoadjuvant imatinib for rectal GISTs; these studies indicated that patients with rectal GISTs who received neoadjuvant imatinib therapy were associated 

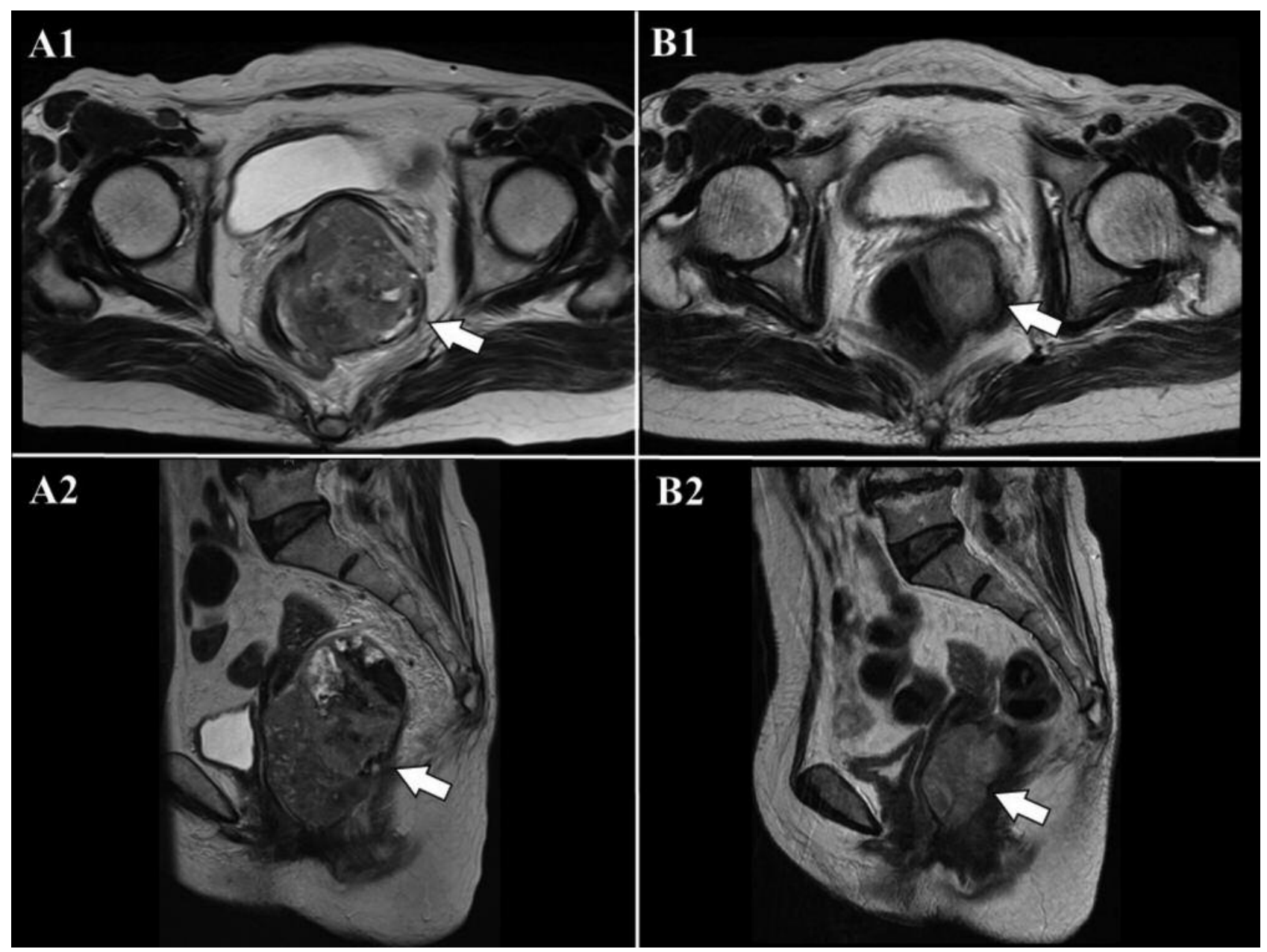

Figure 2. Magnetic resonance imaging scans taken before $(A 1, A 2)$ and after $(B 1, B 2)$ neoadjuvant imatinib therapy for Case 4 . The patient was administered $400 \mathrm{mg}$ of neoadjuvant imatinib, once daily, for 4 months. The maximum tumor diameter decreased from $64 \mathrm{~mm}$ before imatinib treatment to $42 \mathrm{~mm}$ at the time of surgery (arrows), and R0 resection was achieved.

with higher rates of R0 resections and improved disease-free and overall survivals $(17,18,30)$. In the current study, 5 patients were treated with a combination of neoadjuvant imatinib therapy and surgery, and R0 (complete) and R1 resections were performed in 4 and 1 of the patients, respectively. This result was comparable to those of previous studies, where the patients underwent transabdominal resections (R0, 62.5-86.7\%; R1, 13.3-37.5\%) $(20,30)$.

The optimal duration of preoperative imatinib therapy for patients with rectal GISTs has not yet been established. Surgery is performed following the maximal tumor responses to imatinib therapy, and prior to the occurrence of secondary mutations, which may occur generally after 6-12 months (31, 32 ). In the current study, surgery was performed after 3-12 months of treatment.
The decision of the appropriate surgical approach depends on several factors, including tumor size, location, and the presence of local invasion. There are mainly two types of surgeries: transanal local excision and transabdominal resection. The latter includes abdominoperineal resection, pelvic exenteration, anterior resection, and, recently, ISR (22). For small GISTs located close to the anal verge, transanal excision is the treatment of choice (20). However, this treatment is unsuitable for large GISTs because it is difficult to secure clear resection margins with transanal local excisions, when GISTs come in contact with adjacent organs, such as the prostate or vagina (22). A recent study including 39 patients with rectal GISTs reported that the local removal of tumors resulted in 11 of 21 (52\%) R0, 9 of 21 (43\%) R1, 1 of $21(5 \%) \mathrm{R} 2$ resections (30). For large GISTs situated in the 
lower rectum, abdominoperineal resections are often necessary to accomplish oncological complete resections.

ISR aims to preserve anal function in patients with very low rectal cancers (33). A recent study on treatment with laparoscopic ISR following imatinib treatment for low rectal GISTs, reported that laparoscopic ISR was found to be safe and feasible for downsized low rectal GISTs (22). During laparoscopic ISR, the reaching to the level of intersphincteric plane via the abdomen, and resection of distal margins can be performed under a direct view, thus potentially obtaining better safety margins than those obtained by the transanal approach and preserving the function of the anal sphincter, and hence, avoiding a permanent stoma. Laparoscopic surgery has been widely accepted as a minimally invasive surgical procedure. Although laparoscopic rectal surgery is challenging, a magnified view provides more precise images of the anatomy and the accuracy of the performed surgery. Dissecting tissue between the tumor and the seminal vesicles, prostate, or vagina to the level of the intersphincteric groove is difficult by laparotomy, but may be more feasible by laparoscopic surgery. There were no intraoperative complications, but minor postoperative complications were noted. During the follow-up period, recurrence was observed in only 1 patient, and the others were alive without evidence of local or systemic recurrence. Based on our results, we propose that laparoscopic or robotic assisted laparoscopic ISR is a promising alternative for low rectal GISTs.

This study is limited by its retrospective design and small sample size, and was carried out at a single institution. Therefore, additional studies with larger populations are required to confirm our findings.

In conclusion, this study demonstrated that a reduction in tumor size after preoperative imatinib therapy aided the performance of the sphincter-preserving procedure. A combination of neoadjuvant imatinib therapy and laparoscopic or robotic ISR for low rectal GISTs is a challenging, but promising, alternative to achieve complete resection margins, and preserve anal sphincter function.

\section{Acknowledgements}

This research is supported by Grants-in-Aid for Scientific Research (A: grant number, 16H02672; C: grant number, 16K07143; C: grant number, 16K07161; C: grant number, 17K10620; C: grant number, 17K10621; and C: grant number, 17K10623) from Japan Society for the promotion of Science. Additionally, this research is supported by the Project for Cancer Research and Therapeutic Evolution (PCREATE, grant number: 16cm0106502h0001) from the Japan Agency for Medical Research and Development (AMED).

\section{References}

1 Miettinen M, Sarlomo-Rikala M and Lasota J: Gastrointestinal stromal tumors: Recent advances in understanding of their biology. Hum Pathol 30(10): 1213-1220, 1999.
2 Miettinen M and Lasota J: Gastrointestinal stromal tumors definition, clinical, histological, immunohistochemical, and molecular genetic features and differential diagnosis. Virchows Arch 438(1): 1-12, 2001.

3 Goettsch WG, Bos SD, Breekveldt-Postma N, Casparie M, Herings RM and Hogendoorn PC: Incidence of gastrointestinal stromal tumours is underestimated: Results of a nation-wide study. Eur J Cancer 41(18): 2868-2872, 2005.

4 Mazur MT and Clark HB: Gastric stromal tumors. Reappraisal of histogenesis. Am J Surg Pathol 7(6): 507-519, 1983.

5 Saul SH, Rast ML and Brooks JJ: The immunohistochemistry of gastrointestinal stromal tumors. Evidence supporting an origin from smooth muscle. Am J Surg Pathol 11(6): 464-473, 1987.

6 Miettinen M: Gastrointestinal stromal tumors. An immunohistochemical study of cellular differentiation. Am J Clin Pathol 89(5): 601-610, 1988.

7 Hirota S, Isozaki K, Moriyama Y, Hashimoto K, Nishida T, Ishiguro S, Kawano K, Hanada M, Kurata A, Takeda M, Muhammad Tunio G, Matsuzawa Y, Kanakura Y, Shinomura Y and Kitamura Y: Gain-of-function mutations of c-kit in human gastrointestinal stromal tumors. Science 279(5350): 577-580, 1998.

8 Tran T, Davila JA and El-Serag HB: The epidemiology of malignant gastrointestinal stromal tumors: An analysis of 1,458 cases from 1992 to 2000. Am J Gastroenterol 100(1): 162-168, 2005.

9 Dematteo RP, Heinrich MC, El-Rifai WM and Demetri G: Clinical management of gastrointestinal stromal tumors: before and after STI-571. Hum Pathol 33(5): 466-477, 2002.

10 Demetri GD, von Mehren M, Blanke CD, Van den Abbeele AD, Eisenberg B, Roberts PJ, Heinrich MC, Tuveson DA, Singer S, Janicek M, Fletcher JA, Silverman SG, Silberman SL, Capdeville R, Kiese B, Peng B, Dimitrijevic S, Druker BJ, Corless C, Fletcher CD and Joensuu H: Efficacy and safety of imatinib mesylate in advanced gastrointestinal stromal tumors. N Engl J Med 347(7): 472-480, 2002.

11 Verweij JJ: Progression-free survival in gastrointestinal stromal tumours with high-dose imatinib: Randomised trial. The Lancet (British edition) 364(9440): 1127-1134, 2004.

12 Dematteo RP, Ballman KV, Antonescu CR, Maki RG, Pisters PW, Demetri GD, Blackstein ME, Blanke CD, von Mehren M, Brennan MF, Patel S, McCarter MD, Polikoff JA, Tan BR and Owzar K; American College of Surgeons Oncology Group (ACOSOG) Intergroup Adjuvant GIST Study Team: Adjuvant imatinib mesylate after resection of localised, primary gastrointestinal stromal tumour: A randomised, double-blind, placebo-controlled trial. The Lancet (British edition) 373(9669): 1097-1104, 2009.

13 Joensuu H, Eriksson M, Sundby Hall K, Hartmann JT, Pink D, Schütte J, Ramadori G, Hohenberger P, Duyster J, Al-Batran SE, Schlemmer M, Bauer S, Wardelmann E, Sarlomo-Rikala M, Nilsson B, Sihto H, Monge OR, Bono P, Kallio R, Vehtari A, Leinonen $\mathrm{M}$, Alvegård $\mathrm{T}$ and Reichardt $\mathrm{P}$ : One vs three years of adjuvant imatinib for operable gastrointestinal stromal tumor: A randomized trial. JAMA 307(12): 1265-1272, 2012.

14 Fiore M, Palassini E, Fumagalli E, Pilotti S, Tamborini E, Stacchiotti S, Pennacchioli E, Casali PG and Gronchi A: Preoperative imatinib mesylate for unresectable or locally advanced primary gastrointestinal stromal tumors (GIST). Eur J Surg Oncol 35(7): 739-745, 2009.

15 Eisenberg BL, Harris J, Blanke CD, Demetri GD, Heinrich MC, Watson JC, Hoffman JP, Okuno S, Kane JM and von Mehren M: 
Phase II trial of neoadjuvant/adjuvant imatinib mesylate (IM) for advanced primary and metastatic/recurrent operable gastrointestinal stromal tumor (GIST): Early results of RTOG 0132/ACRIN 6665. J Surg Oncol 99(1): 42-47, 2009.

16 Namikawa T, Munekage E, Munekage M, Maeda M, Yatabe T, Kitagawa H, Sakamoto K, Obatake M, Kobayashi M and Hanazaki K: Synchronous Large Gastrointestinal Stromal Tumor and Adenocarcinoma in the Stomach Treated with Imatinib Mesylate Followed by Total Gastrectomy. Anticancer Res 36(4): 1855-1859, 2016.

17 Wang JP, Wang T, Huang MJ, Wang L, Kang L and Wu XJ: The role of neoadjuvant imatinib mesylate therapy in sphincterpreserving procedures for anorectal gastrointestinal stromal tumor. Am J Clin Oncol 34(3): 314-316, 2011.

18 Machlenkin S, Pinsk I, Tulchinsky H, Ziv Y, Sayfan J, Duek D, Rabau M and Walfisch S: The effect of neoadjuvant imatinib therapy on outcome and survival after rectal gastrointestinal stromal tumour. Colorectal Dis 13(10): 1110-1115, 2011.

19 Tielen R, Verhoef C, van Coevorden F, Reyners AK, van der Graaf WT, Bonenkamp JJ, van Etten B and de Wilt JH: Surgical management of rectal gastrointestinal stromal tumors. J Surg Oncol 107(4): 320-323, 2013.

20 Liu H, Yan Z, Liao G and Yin H: Treatment strategy of rectal gastrointestinal stromal tumor (GIST). J Surg Oncol 109(7): 708713, 2014.

21 Wilkinson MJ, Fitzgerald JE, Strauss DC, Hayes AJ, Thomas JM, Messiou C, Fisher C, Benson C, Tekkis PP and Judson I: Surgical treatment of gastrointestinal stromal tumour of the rectum in the era of imatinib. Br J Surg 102(8): 965-971, 2015.

22 Fujimoto Y, Akiyoshi T, Konishi T, Nagayama S, Fukunaga Y and Ueno $\mathrm{M}$ : Laparoscopic sphincter-preserving surgery (intersphincteric resection) after neoadjuvant imatinib treatment for gastrointestinal stromal tumor (GIST) of the rectum. Int J Colorectal Dis 29(1): 111-116, 2014.

23 Wachter N, Wörns MA, dos Santos DP, Lang H, Huber T and Kneist W: Transanal minimally invasive surgery (TAMIS) approach for large juxta-anal gastrointestinal stromal tumour. Journal Min Access Surg 12(3): 289-291, 2016.

24 Joensuu H: Risk stratification of patients diagnosed with gastrointestinal stromal tumor. Human Pathol 39(10): 14111419, 2008.
25 Eisenhauer EA, Therasse P, Bogaerts J, Schwartz LH, Sargent D, Ford R, Dancey J, Arbuck S, Gwyther S, Mooney M, Rubinstein L, Shankar L, Dodd L, Kaplan R, Lacombe D and Verweij J: New response evaluation criteria in solid tumours: revised RECIST guideline (version 1.1). Eur J Cancer (1990) 45(2): 228-247, 2009.

26 Kanda Y: Investigation of the freely available easy-to-use software 'EZR' for medical statistics. Bone Marrow Transplant 48(3): 452-458, 2013.

27 Nakamura T, Ihara A, Mitomi H, Kokuba Y, Sato T, Ozawa H, Hatade K, Onozato W and Watanabe M: Gastrointestinal stromal tumor of the rectum resected by laparoscopic surgery: Report of a case. Surg Today 37(11): 1004-1008, 2007.

28 Goh BK, Chow PK, Chuah KL, Yap WM and Wong WK: Pathologic, radiologic and pet scan response of gastrointestinal stromal tumors after neoadjuvant treatment with imatinib mesylate. Eur J Surg Oncol 32(9): 961-963, 2006.

29 Cananzi FC, Judson I, Lorenzi B, Benson C and Mudan S: Multidisciplinary care of gastrointestinal stromal tumour: A review and a proposal for a pre-treatment classification. European J Surg Oncol 39(11): 1171-1178, 2013.

30 Jakob J, Mussi C, Ronellenfitsch U, Wardelmann E, Negri T, Gronchi A and Hohenberger P: Gastrointestinal stromal tumor of the rectum: Results of surgical and multimodality therapy in the era of imatinib. Ann Surg Oncol 20(2): 586-592, 2013.

31 Casali PG, Jost L, Reichardt P, Schlemmer M and Blay JY: Gastrointestinal stromal tumors: ESMO clinical recommendations for diagnosis, treatment and follow-up. Ann Oncol 19(suppl 2): ii35-ii38, 2008.

32 Haller F, Detken S, Schulten H, Happel N, Gunawan B, Kuhlgatz $J$ and Füzesi L: Surgical management after neoadjuvant imatinib therapy in gastrointestinal stromal tumours (GISTs) with respect to imatinib resistance caused by secondary kit mutations. Ann Surg Oncol 14(2): 526-532, 2007.

33 Schiessel R, Karner-Hanusch J, Herbst F, Teleky B and Wunderlich M: Intersphincteric resection for low rectal tumours. Br J Surg 81(9): 1376-1378, 1994.

Received June 29, 2017

Revised July 9, 2017

Accepted July 10, 2017 